\title{
Welcome to the 10th volume of Pain Management
}

\author{
Rhiannon Finnie $*, 1$ \\ ${ }^{1}$ Future Science Group, Unitec House, 2 Albert Place, London, N3 1QB, UK \\ *Author for correspondence: r.finnie@futuremedicine.com
}

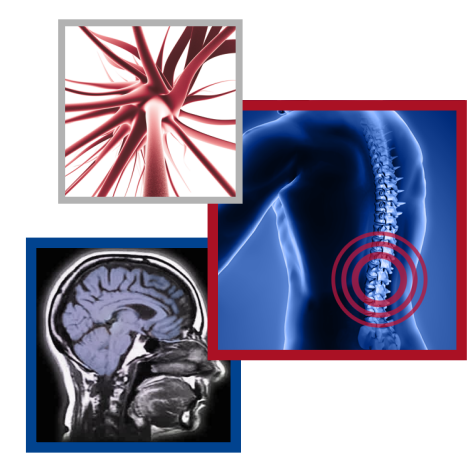

First draft submitted: 4 December 2019; Accepted for publication: 4 December 2019; Published online:

9 January 2020

Keywords: $2019 \bullet$ acute pain $\bullet$ analgesics $\bullet$ demographics $\bullet$ endometriosis $\bullet$ foreword $\bullet$ opioids $\bullet$ pain management - publications

To all our readers, we would like to take this opportunity to wish you all a Happy New Year. We are delighted to welcome you to the 10th volume of Pain Management and are pleased to introduce the first issue of 2020.

We would like to take this opportunity to reflect on the past 12 months from the perspective of the journal. We also want to thank all our authors, readers and reviewers, as well as our esteemed Editorial Board members for their ongoing support.

We are very much looking forward to working with everyone in 2020.

\section{Content highlights of 2019}

The year of 2019 was another exciting year for the journal with the continued publication of timely, high-quality manuscripts in the field of pain management. We are proud to present some of our content highlights from last year.

At the time of writing (December 2019), our most read article of 2019 was a Research Article entitled, "Pooled Phase III safety analysis of sufentanil sublingual tablets for short-term treatment of moderate-to-severe acute pain," written by Miner $e t a l$. [1]. This study involving 804 patients and that concluded sufentanil sublingual tablets were well-tolerated with most adverse effects only being mild or moderate in severity.

Another Research Article that was popular in 2019 was, "Frequency, nature and management of patient-reported severe acute pain episodes in the over-the-counter setting: results of an online survey," by C Hersch, C Denis and D Sugár [2].

Our most read Review article was entitled, "Clinical evaluation of the oral gonadotropin-releasing hormoneantagonist elagolix for the management of endometriosis-associated pain," by HS Taylor, EC Dun and K Chwalisz [3]. This article explored the current understanding of endometriosis-associated pain, the role of estrogen and the clinical development of elagolix.

"Perspectives on cannabis as a substitute for opioid analgesics," was another popular Review article published in 2019 written by SP Khan, TA Pickens and DJ Berlau [4].

Several Editorials were published in 2019 that provided snapshots of important and fascinating topics in the field of pain management. Some of the most popular included: "Diet therapy in the management of chronic pain: better diet less pain?" by U Philpot and MI Johnson [5] and "A new way of thinking about pain," by JD Loeser [6]. As well as these, the most read Editorial of 2019 was "Hemiplegic shoulder pain in people with stroke: present and the future," provided by P Kumar [7].

\section{Readership demographics}

It is fantastic to see that Pain Management has continued its wide reach throughout 2019 with readers based all over the globe. As seen in previous years, readers in 2019 were mainly from North America (54\%) and Europe (21\%; Figure 1). The region with the most readers was North America, followed by the UK. There was also a slight increase of readers from Asia in 2019, but similar proportions were from Africa, Oceania and South America.

Future $\because$ Medicine 


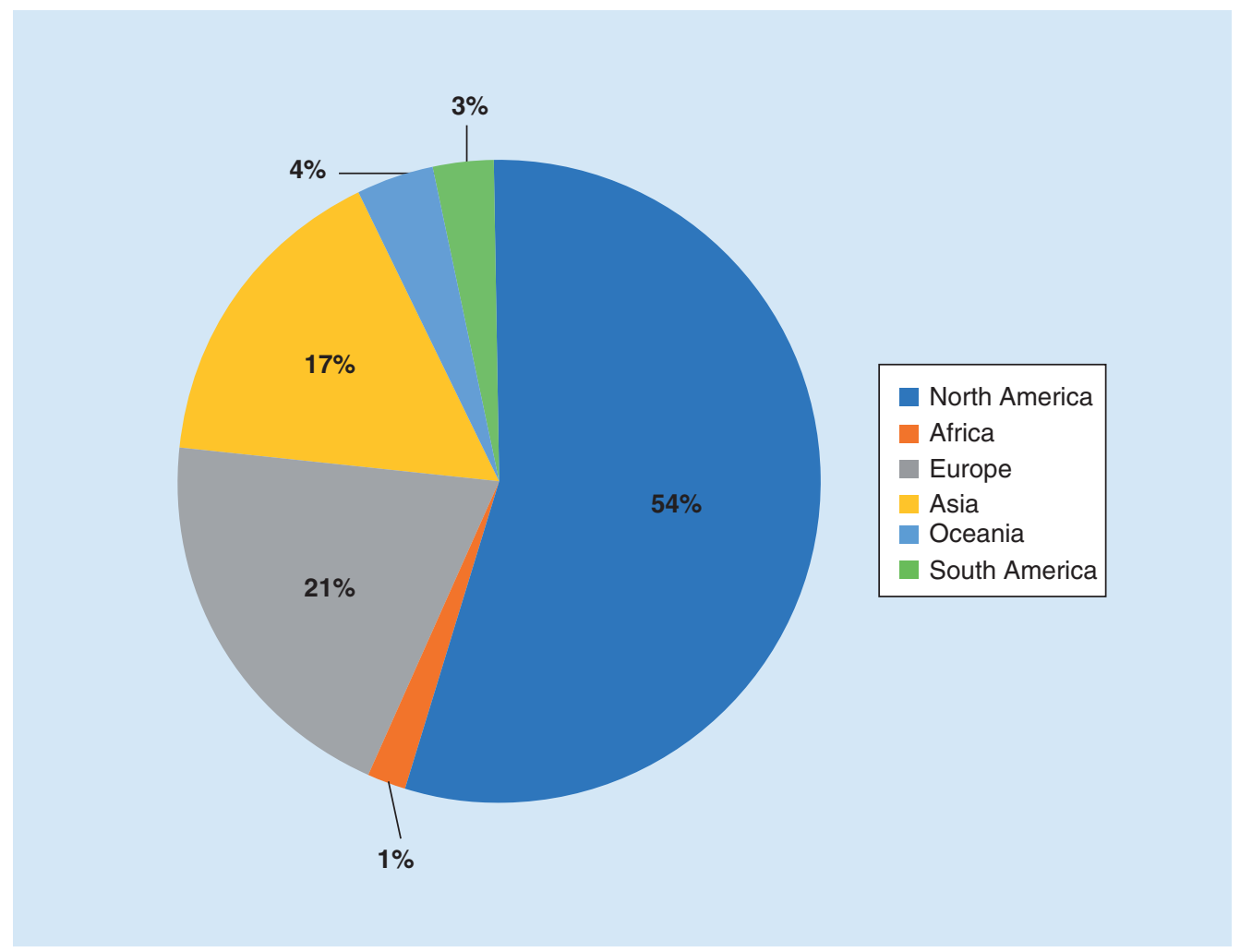

Figure 1. Readership demographics for Pain Management in 2019.

\section{Authorship demographics}

It is also interesting to see where the content of Pain Management was received from in 2019. In 2019, there was an $11 \%$ increase in content contributed from North America compared with the previous year [8]. As a result, there were slight decreases in the proportions from Europe, Asia and South America; however, the proportion from Oceania remained the same (Figure 2). We continue to welcome manuscript submissions from across the world and encourage unsolicited article proposals.

\section{Social media}

Pain Management continues to be active across social media, including Twitter (@fsgpmt) [9], where we have seen an approximate increase of $25 \%$ in the number of followers since 2018 . We are also associated with the digital site, Neuro Central, hosted by Future Science Group [10] and their LinkedIn group [11]. We are delighted to continue this collaboration and encourage our readers to connect with us via social medial as we continue into 2020.

\section{Conclusion}

As always, we welcome all feedback from the community regarding the direction our journal is taking and any suggestions for topics you wish to see covered in Pain Management. As mentioned previously, we accept unsolicited articles of all forms, including Original Research Articles, Reviews and Opinion Articles (e.g., Editorials and Commentaries). Please get in contact with the Commissioning Editor of the journal if you are interested in submitting to the journal. In particular, we are looking for submissions surrounding key areas such as:

- Physiology and mechanisms of pain;

- Transition from acute to chronic pain;

- Therapeutic options;

- New concepts and breakthroughs in pain control;

- Interventional procedures;

- Nonpharmacologic approaches; 


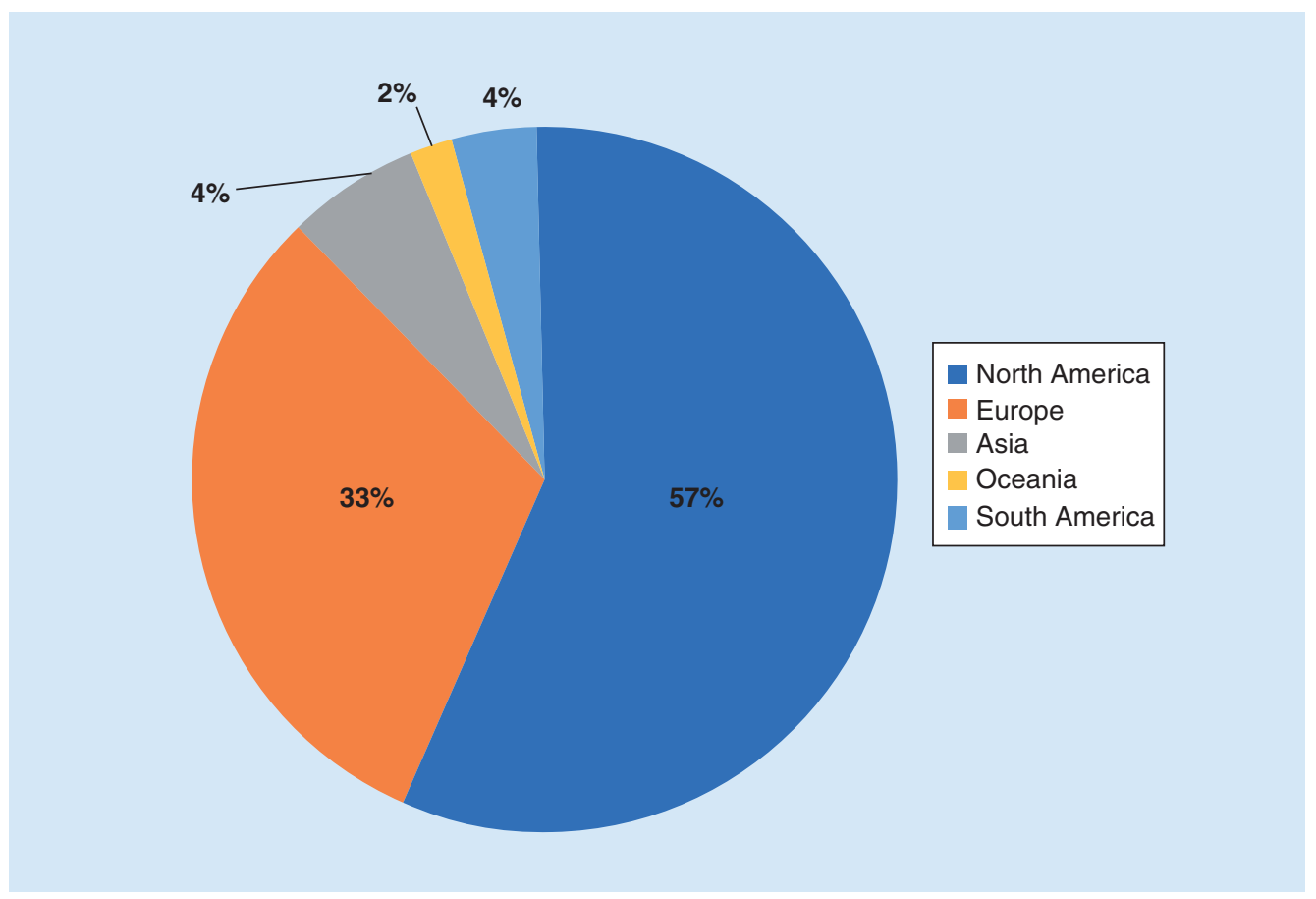

Figure 2. Authorship demographics demographics for Pain Management in 2019.

- Acute and postoperative pain control;

- Pain management in oncology;

- Special pain syndromes;

- Palliative care;

- Pediatric and aging health;

- Pharmacology and addiction/abuse of pain medication;

- Adverse events and drug safety;

- Pharmacoeconomics, outcomes research and quality of life.

Finally, we would like to thank everyone for their continued engagement and support with the journal and we are excited to continue working with you all in the coming year.

Financial \& competing interests disclosure

R Finnie is an employee of Future Medicine Ltd. The author has no other relevant affiliations or financial involvement with any organization or entity with a financial interest in or financial conflict with the subject matter or materials discussed in the manuscript apart from those disclosed.

No writing assistance was utilized in the production of this manuscript.

\section{References}

1. Miner JR, Melson TI, Leiman D et al. Pooled Phase III safety analysis of sufentanil sublingual tablets for short-term treatment of moderate-to-severe acute pain. Pain Manag. 9(3), 259-271 (2019).

2. Hersch C, Denis C, Dalma S. Frequency, nature and management of patient-reported severe acute pain episodes in the over-the-counter setting: results of an online survey. Pain Manag. 9(4), 379-387 (2019).

3. Taylor HS, Dun EC, Chwalisz K. Clinical evaluation of the oral gonadotropin-releasing hormone-antagonist elagolix for the management of endometriosis-associated pain. Pain Manag. 9(5), 497-515 (2019).

4. Khan SP, Pickens TA, Berlau DJ. Perspectives on cannabis as a substitute for opioid analgesics. Pain Manag. 9(2), 191-203 (2019).

5. Philpot U, Johnson MI. Diet therapy in the management of chronic pain: better diet less pain? Pain Manag. 9(4), 335-338 (2019).

6. Loeser JD. A new way of thinking about pain. Pain Manag. 9(1), 5-7 (2019).

7. Kumar P. Hemiplegic shoulder pain in people with stroke: present and the future. Pain Manag. 9(2), 107-110 (2019). 
8. Bough A. Welcome to the ninth volume of Pain Management. 9(1), 1-4 (2019).

9. Pain Management journal. Twitter (2019). https://twitter.com/fsgpmt

10. Neuro Central (2019). http://www.neuro-central.com/

11. Future Science Group Neuro Central. LinkedIn (2019). http://www.linkedin.com/company/neuro-central/ 